\title{
A case of Undifferentiated connective tissue disease
}

\author{
Chatterjee $A,{ }^{1}$ Chatterjee $\mathrm{K}^{2}$ Sarkar $\mathrm{N},{ }^{3}$ \\ ${ }^{1}$ Assistant Professor, ${ }^{2}$ Senior Resident, Department of Pediatrics, Calcutta National Medical College \\ ${ }^{3}$ Registrar, Apollo Gleaneagles Hospital,Kolkata.
}

\section{ABSTRACT}

Undifferentiated connective tissue disease is an overlap syndrome in which the features of more than one disease is present but their complete diagnosis is lacking. We are presenting an 11year child with fever, arthritis, polyserositis, myalgia, nephritis, sclerodactyly with positive anti-dsDNA and anti-Smith antibody. She improved with prednisolone and cyclophosphamide.

Key Words: Undifferentiated connective tissue disease, polyserositis, arthritis, myalgia, sclerodactyly.

\section{INTRODUCTION}

Connective tissue disease result from autoimmune processes that lead to inflammation of target organs. Rarely,children develop overlap syndromes, one such is mixed connective tissue disease(MCTD) where features of two or more major rheumatic disorders are seen-juvenile rheumatoid arthritis(JRA), systemic lupus erythematosus (SLE), juvenile dermatomyositis(JDM) and systemic sclerosis. Children may also have undifferentiated connective tissue disease in which manifestations strongly suggest but do not meet diagnostic criteria for a specific rheumatic disease.

\section{CASE REPORT}

An 11 year old girl presented with fever and weight loss for 1year, joint pain and swelling for 6 months, muscle pain for 2 months and respiratory distress for 2days.Fever was continuous, high grade with a maculopapular, erythematous rash on the trunk, non itchy, painless, lasting for 7-8days. Fever continued

Correspondence: Dr. Kaushani Chatterjee

E-mail: kaushani_10@yahoo.com and investigation showed ESR-95mm/hour. After 4 months of fever ,she developed pain, swelling and movement restriction of the large joints, it was symmetric with no small joint involvement. She is the third child of a non-consanguinous marriage, with no significant past illness and no family history of musculoskeletal disease.

She was admitted to a hospital at 8 months of fever with joint pain and swelling, weakness and pallor, cervical lymphadenopathy and abdominal distention. Investigation showed $\mathrm{Hb}-8.3 \mathrm{gm} /$ $\mathrm{dL}$, ESR-60mm/hour, malaria parasite, sputum for AFB, bone marrow, mantoux test, chest x-ray, HIV 1 and 2 all were normal. Ultrasound abdomen showed hepatomegaly. She was discharged with symptomatic treatment.

She came to us after another 4 months, now having high grade fever, severe respiratory distress and chest pain, severe pallor, generalised bodyache and stiffness of fingers .On examination, she had severe pallor, pedal edema, engorged neck veins, tachycardia, tachypnea, BP-80/40 mmHg, temperature-40.5degree Celsius and patchy 
Journal of College of Medical Sciences-Nepal, 2013, Vol-9, No-4,

alopecia. Her weight was $20 \mathrm{~kg}\left(<3^{\text {rd }}\right.$ centile $)$ and height $-155 \mathrm{~cm}\left(85^{\text {th }}\right.$ centile on WHO chart).She was orthopenic with crepitations in both lung fields, cardiomegaly, gallop rhythm, soft hepatomegaly and ascites. There was generalised myalgia, generalised attitude of flexion in bilateral knee, elbow and wrist joints and partial flexion of fingers. Other systems were normal. There was no history of hematuria or any urinary abnormality, no history of photosensitivity or Raynaud's phenomena. Investigation showed $\mathrm{Hb}-4 \mathrm{gm} / \mathrm{dL}, \mathrm{ESR}-120 \mathrm{~mm} /$ hour, TC-12600(N72 L24 M2 E2),Normoblast-56/ 100 leukocytes, retic count-10, DCT positive,SGPT-130U/L,SGOT-213U/L, rest of liver function test was normal, ECG-low voltage complexes with ST elevation; Echo-pericardial effusion with impending cardiac tamponade, ultrasound abdomen-hepatomegaly with ascites. Pericardial tap was done, cell count $-100 / \mathrm{cmm}$, ADA negative, other parameters were normal. Further investigation revealed triglyceride-271mg/ dL, LDH was grossly elevated to 2316U/L, CPK135U/L, ANA-1:1280.Fundoscopic examination was normal. Skin biopsy showed "dermis packed with homogenous bundles of collagen fibres" features consistent with scleroderma. Muscle biopsy "inflammatory infiltrate in perivascular location and between muscle fibres" suggestive of dermatomyositis. X-ray examination of the joints revealed nonerosive arthropathy. Antibody panel is shown in Table- 1 .

\section{Table1}

$\begin{array}{ll}\text { Antibody Panel } & \text { Result } \\ \text { Anti SSA } & \text { Negative } \\ \text { Anti SSB } & \text { Negative } \\ \text { Anti Smith } & \text { Positive } \\ \text { Anti dsDNA } & \text { Positive }\end{array}$

Anti U1 RNP Negative

Pulmonary function test showed FEV1-46\%,FVC42\%,PEFR-40\%,FEF25-75-72\%, indicating a restrictive lung defect. HRCT scan however showed only pericardial effusion and no evidence of interstitial lung disease. Barium swallow X-ray was normal. Kidney biopsy revealed membranoproliferative glomerulonephritis, compatible with lupus nephritis, WHO,class-4. EMG/NCV of all four limbs showed motorpolyradiculopathy with proximal myopathy. Antiphospholipid antibody was negative while C3 and $\mathrm{C} 4$ counts were below normal at the beginning (C3-66mg/dL,C4-10mg/dl) which later normalized (C3-118mg/dL,C4-32mg/dL) with treatment.

The child was treated with oral prednisolone at $2 \mathrm{mg} / \mathrm{kg} /$ day but no improvement was observed in the symptomatology by 7 days, so pulse IV methylprednisolone $30 \mathrm{mg} / \mathrm{kg} /$ day was given for 3 consecutive days. This was followed by oral daily prednisolone. Supportive therapy with oral iron, folate, calcium, multivitamins and ranitidine was given.Kidney biopsy report prompted us to institute IV pulse cyclophosphamide $750 \mathrm{mg} / \mathrm{m} 2 /$ month. Following therapy, the subsequent improvement both clinically and physically was dramatic. Physiotherapy was started to improve joint mobility. At discharge after 1month of indoor treatment, she was able to stand erect, squat and stand up unassisted and the mobility of small joints of hand had also greatly improved.

\section{DISCUSSION}

The diagnosis of the case put us in a dilemma as to whether it is a case of MCTD, a case of SLE, scleroderma or dermatomyositis. Diagnosis of MCTD is based on Sharp's criteria (Table-2) in 
A case of Undifferentiated connective tissue disease which a definite, probable or possible diagnosis requires the presence of positive antiU1RNP which was absent in this case. The Bohan and Peter criteria for JDM requires the presence of pathognomonic rash (heliotrope discolouration of the eyelids and Gottron's papules) along with two of the other 4(1.proximal muscle weakness 2. Elevated muscle enzymes 3. EMG changes of myopathy 4. Muscle biopsy showing necrosis and degeneration).In this case as the rash was absent, a complete diagnosis of JDM could not be made. The diagnosis of scleroderma is made by the presence of the major criteria (proximal scleroderma) or 2 of the 3 minor criteria (1.sclerodactyly 2. Digital pitting scar 3. Bibasilar pulmonary fibrosis).In this case, the presence of sclerodactyly alone rules out the definite diagnosis of scleroderma. The criteria for classification of SLE(1997 ACR criteria) in which 4 of the 11 criteria are to be met, is confirmed. Thus reviewing the case, criteria for SLE was met and that of JDM and scleroderma were partially met, causing the diagnostic dilemma. An entity "undifferentiated connective tissue disease" was found on further search of literature wherein the full diagnostic criteria required for MCTD is not met. Our case seems to belong to this category and

can thus be classified as undifferentiated connective tissue disease.

\section{Table2 : Diagnostic criteria for Mixed Connective Tissue Disease-}

\section{MAJOR Criteria}

1. Severe myositis

2. Pulmonary involvement,with 1 or more of the following:DLco $<70 \%$ normal, pulmonary hypertension or proliferative vascular lesions on lung biopsy

3. Raynaud's phenomenon or esophageal Hypomotility

4. Pleuriti

4. Swollen hands or sclerodactyly

5. Highest observed anti-ENA titer $>=1: 10000$ $\&$ anti RNP positive neuropathy

8. Malar rash

9. Thrombocytopenia $(<100000 / \mathrm{mm} 3)$

\section{MINOR Criteria}

\section{Alopecia}

2.Leukopenia (<4000WBC/mm3)

3.Anemia $(<=10 \mathrm{~g} / \mathrm{dL}-$ women, $<=12 \mathrm{~g} / \mathrm{dL}$ -

men)

5.Pericarditis

6.Arthritis

7.Trigeminal

10. Mild myositis 
Journal of College of Medical Sciences-Nepal, 2013, Vol-9, No-4,

\section{Diagnosis \\ Definite}

A. 4 major criteria: anti U1RNP positive with anti ENA $>=1: 4000$

\section{Probable}

A. 3 major criteria

B. 2 major criteria (including at least 1 or more of nos. $1,2 \& 3$ ) plus 2 minor criteria anti U1 RNP positive with anti ENA >=1:1000

\section{Possible}

A. 3 major criteria:no other requirements

B. 2 major criteria: plus anti U1 RNP positive with anti ENA >=1:100

C. 1 major and 3 minor criteria: plus anti U1 RNP positive with anti ENA $>=1: 100$

\section{Exclusion}

\section{Definite}

Positive for anti Sm antibodies

Probable \& Possible : none

DLco-Single breath CO diffusing capacity of the lungs, ENA extractable nuclear antigen,U1 RNPUridine rich ribonucleoprotein.

\section{ACKNOWLEDGEMENT}

We would like to acknowledge the assistance of Dr. Bholanath Aich in diagnosis and management of the patient. We would also like to thank Dr.S.Kanjilal and Dr.S.Dolui for their valuable opinion. Special mention must be made of Dr.Gautam Das who helped us with the interventions and Dr.Suman Das for his support.

\section{REFERENCES}

1. Sharp GC, Irvin WS,Tan EM, et al: Mixed Connective Tissue Disease: an apparently distinct rheumatic syndrome associated with a specific antibody to an extractable nuclear antigen.Am J Med 1972;52;148-159
2. Cassidy JT, Petty RE; Overlap Syndromes; In Cassidy JT, Petty RE eds. "Text book of pediatric rheumatology" $4^{\text {th }}$ edition, Philadelphia,W.B Saunders company2001;544552.

3. Sharp GC: Diagnostic criteria for classification of MCTD. In Kasukawa R, Sharp GC: Mixed connective tissue disease and Anti-Nuclear Antibodies. Amsterdam, The Netherlands, Excerpta Medica 1987; pp 23-32.

4. Cassidy JT, Zullan F; The Systemic Sclerodermas and related disorders; In Cassidy JT, Petty RE eds."Text book of pediatric rheumatology"; $4^{\text {th }}$ ed. Philadelphia, WB Saunders Company 2001;442-465

5. Miller ML;Scleroderma and Raynaud phenomena; in Nelson Text Book of Pediatrics $; 8^{\text {th }} \quad$ ed. Saunders company,2007,1024-1027

6.Cassidy JT, Lindsley CB; Juvenile Dermatomyositis; in Cassidy JT, Petty RE eds "Text book of pediatric rheumatology", $4^{\text {th }}$ ed ,2001,407-434.

7. Petty RE, Laxer RM; Systemic Lupus Erythematosus; in Cassidy JT,Petty RE eds."Text book of pediatric rheumatology"; $4^{\text {th }}$ ed,2001;342-383.

8. Mosca M, Neri R, Bombadieri S,Undifferentiated Connective tissue disease: A review of literature and a proposal for preliminary classification criteria ; in Clin Exp Rheumatol 1999,Sept-Oct:17(5):615-620.

9. Klein-Gitelman MS, Miller ML: Systemic Lupus Erythematosus; in Nelson Text book of Pediatrics; $\quad 18^{\text {th }} \quad$ ed,Saunders Company,2007,1015-1019.

10.Bohan A,Peter JB: Polymyositis and dermatomyositis; N Engl J Med 292:344,403; 1975 